\title{
Horseshoe Kidney in an 80 Year Old with Chronic Kidney Disease
}

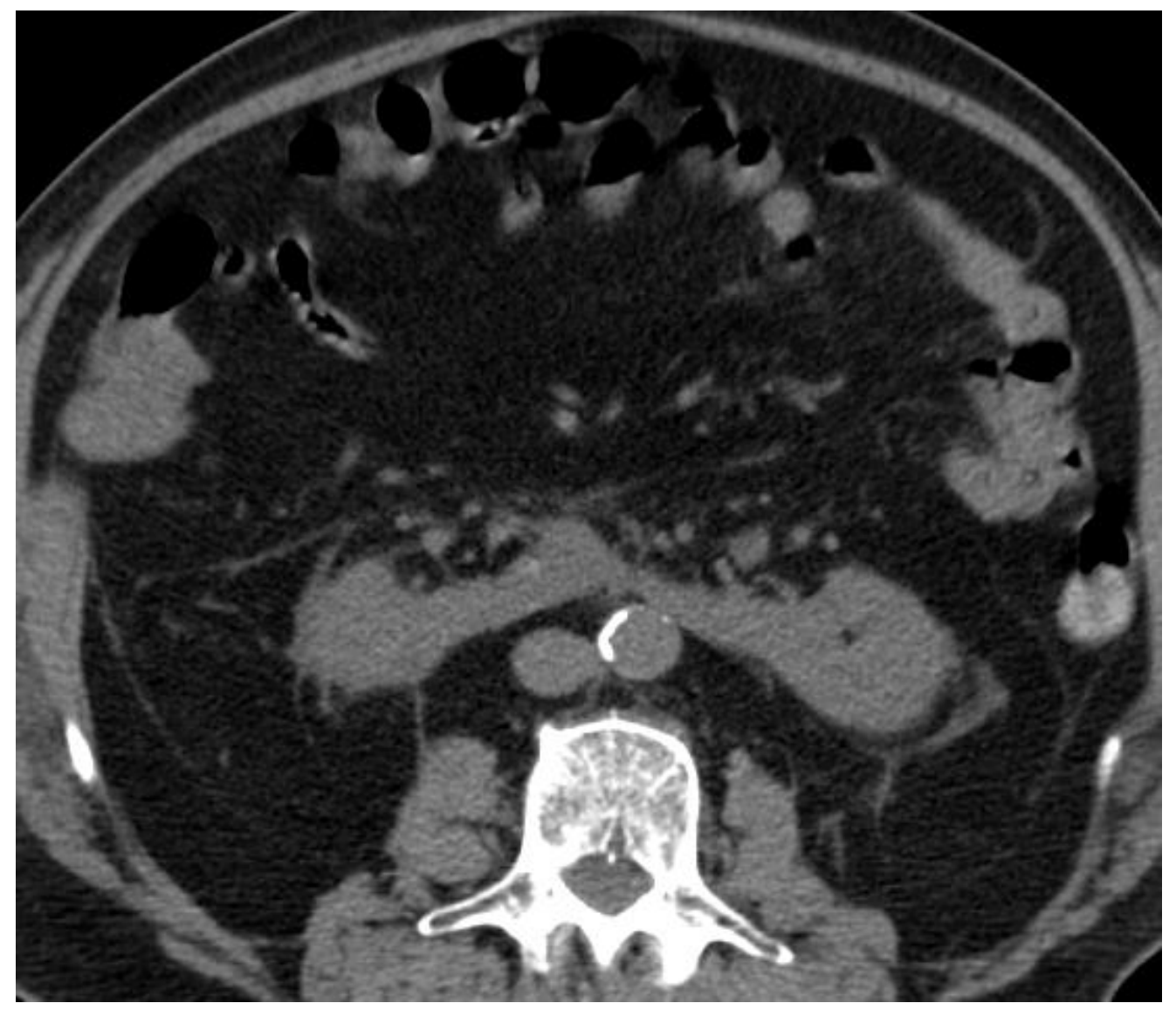

FIGURE 1. This transverse CT section of the abdomen shows complete fusion of the lower poles of the kidneys with a clear isthmus. The fused kidneys are sitt ing lower in the pelvis compared to the location of normal kidneys.

Hema Ramkumar, Syed M. Ahmed*, E. Syed, and J. Tuazon

Department of Medicine, Division of Nephrology and Hypertension, Feinberg School of Medicine, Northwestern University Chicago, IL

E-mail: $\underline{\text { smus.ahmed@gmail.com }}$

Received May 11, 2009; Revised December 3, 2009; Accepted December 4, 2009; Published December 16, 2009

A horseshoe kidney is the most common renal fus ion anomaly, with an incidence of 1/400 worldwide and a male-to-female ratio of 2:1. One theory of the abnormal fusion of the kidneys is that a variation in 
growth of pelvic structures brings the metanephric blastemas close together before renal capsule maturation, resulting in fusion. Consequently, the normal embryonic ascent of the fused kidney is disrupted by the inferior mesenteric artery, leaving the adult horseshoe kidney in a lower position than normal. About $90 \%$ of the time, the lower poles are fused and the excretory renal units and ureters are maintained separately. In the pediatric setting, $90 \%$ of patients are asymptomatic and the most common presentation is a urinary tract infection (UTI). One-third of cases are associated with other congenital or chromosomal anomalies. About one-third of all patients with a horseshoe kidney are asymptomatic. Common complications of a horseshoe kidney abnormality include uretropelvic junction obstruction, recurrent renal calculi, recurrent infections secondary to urine stasis and vesicoureteric reflux, and an increased incidence of renal tumors.

We describe the clinical image of an 80-year-old man with a history of type II diabetes, hypertension, and chronic kidney disease (CKD) who was being evaluated for abdominal pain. A computerized tomography (CT) scan (Fig. 1) of the abdomen was requested and revealed the presence of a horseshoe kidney. A horseshoe kidney does not cause progressive kidney disease. This patient, however, had CKD (estimated GFR of about $20 \mathrm{~m} / \mathrm{min}$ ), most likely associated with type II diabetes and hypertension, and that was unrelated to the horseshoe kidney, which was an incidental finding.

\section{REFERENCES}

1. Cook, W.A. and Stephens, F.D. (1977) Fused kidneys: morphologic study and theory of embryogenesis. Birth Defects Orig. Artic. Ser. 13(5), 327-340.

2. Grainger, R., Murphy, D.M., and Lane, V. (1983) Horseshoe kidney--a review of the presentation, associated congenital anomalies and complications in 73 patients. Ir. Med. J. 76(7), 315-317.

3. Schacht, M.J., Sakowicz, B., and Rao, M.S. (1983) Intermittent abdominal pain in a patient with horseshoe kidney. $J$. Urol. 130(4), 749-751.

4. Boatman, D.L., Kolln, C.P., and Flocks, R.H. (1972) Congenital anomalies associated with horseshoe kidney. J. Urol. 107(2), 205-207.

This article should be cited as follows:

Ramkumar, H., Ahmed, S.M., Syed, E., and Tuazon, J. (2009) Horseshoe kidney in an 80 year old with chronic kidney disease. TheScientificWorldJOURNAL 9, 1346-1347. DOI 10.1100/tsw.2009.165. 


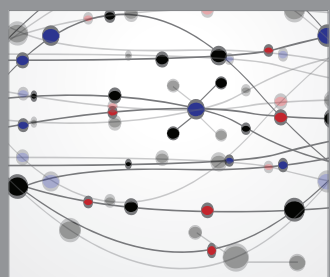

The Scientific World Journal
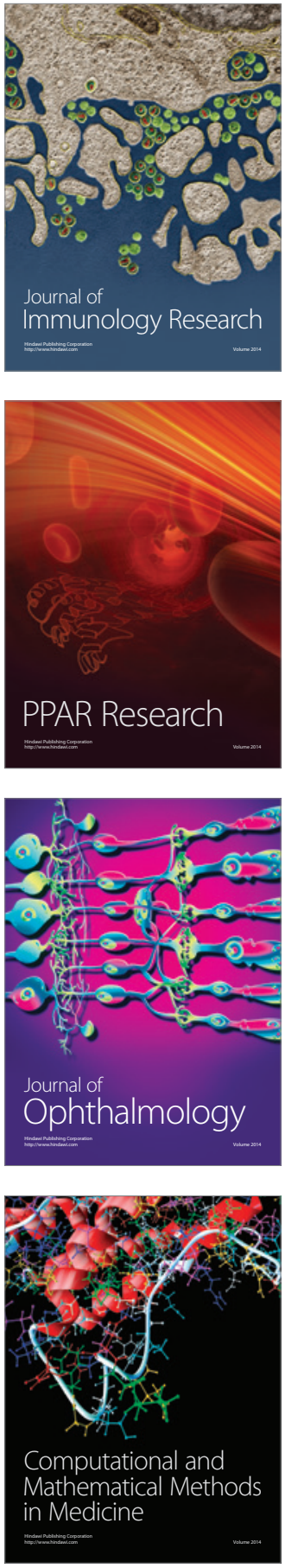

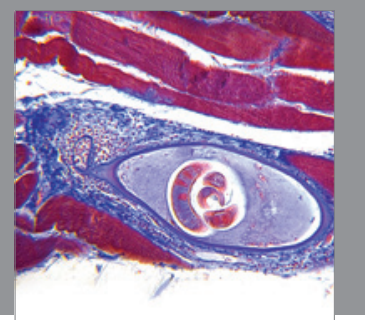

Gastroenterology

Research and Practice
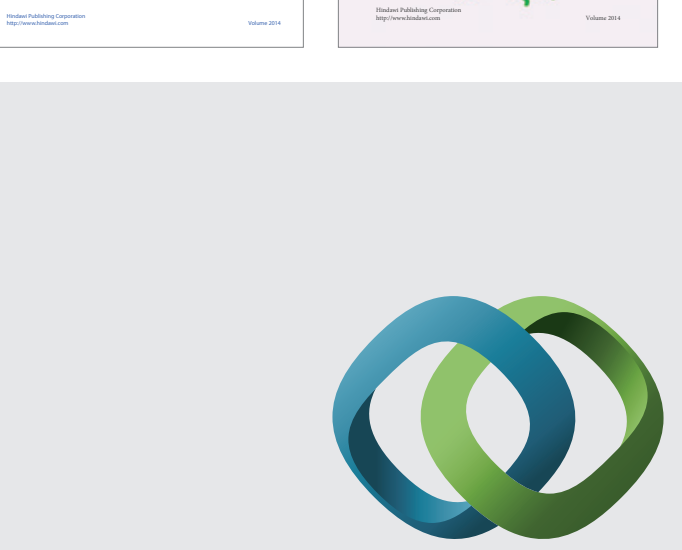

\section{Hindawi}

Submit your manuscripts at

http://www.hindawi.com
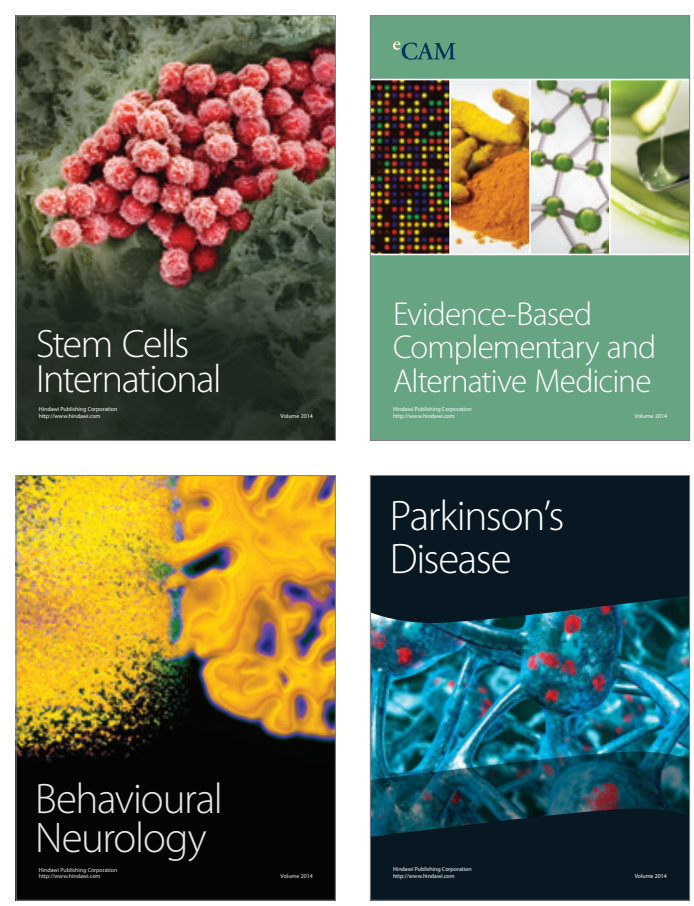

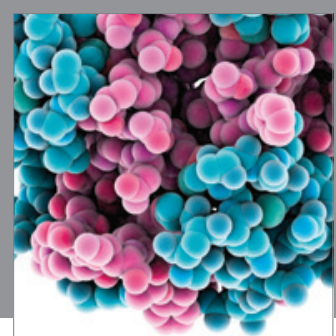

Journal of
Diabetes Research

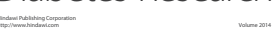

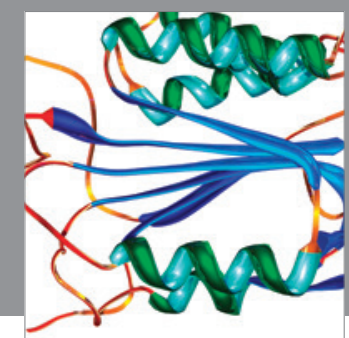

Disease Markers
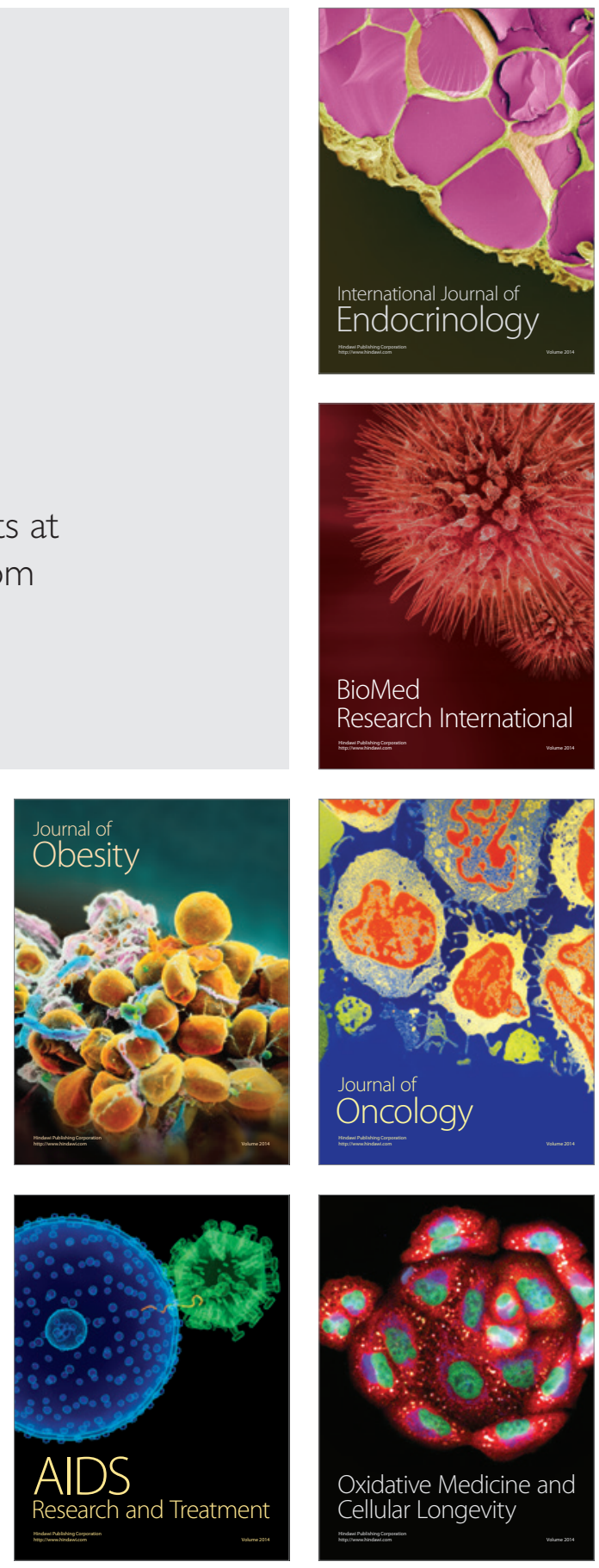